\title{
RESEARCH OF THE PROCESSES OF ACOUSTIC CAVITATION TECHNOLOGY FOR PROCESSING DISPERSED MEDIA
}

I. Nazarenko, I. Bernyk

\section{ABSTRACT}

The operation process of acoustic treatment of technological media is investigated. The assessment and substantiation of methods for studying the parameters of acoustic treatment of technological media is done. The functional relationships between the acoustic parameters of the cavitation apparatus and the rheological properties of the processing technological media have been revealed. The process of staged acoustic treatment of technological media is described. A number of criteria and key parameters were determined, the use of which was carried out as an assessment in the calculation algorithm, depending on certain known initial data of the cavitator and the medium. The values of the input resistance of the compensator are determined and the condition for the maximum transfer of energy from the acoustic apparatus to the technological medium is obtained. To calculate the parameters of the "cavitator - technological medium» ultrasonic cavitation system, an algorithm and method for creating a synergistic system were developed.

\section{KEYWORDS}

Acoustic system, cavitator, medium, bubble, stage, cavitation process, physical, mathematical model, rheological properties, equations, analytical dependences, parameters, amplitude, vibration frequency, intensity, energy, wave resistance.

\subsection{ASSESSMENT AND JUSTIFICATION OF THE CHOICE OF METHODS FOR STUDYING THE PARAMETERS OF ACOUSTIC TREATMENT OF TECHNOLOGICAL MEDIA}

Cavitation technology occupies a leading place in a number of advanced and effective methods for processing liquid media and creating new materials. This technology is being implemented for a number of different technological processes, including dispersion, emulsification, homogenization, degassing, and others [1-6]. Cavitation refers to vibration processes widely used in food [1-3], chemical [4, 5], mechanical engineering [6], construction [7], and other industries. The generally accepted definition of cavitation as a physical phenomenon is the process of the formation of cavities (of a certain size of bubbles) in a fluid flow under the influence of external pressure. Depending on the method of pressure formation in the medium, cavitation can be hydrodynamic or acoustic. 
In hydrodynamic cavitation, a decrease in pressure occurs due to an increase in the local speeds of the liquid flow [5]. If a decrease in pressure is due to the passage of acoustic waves of a sound or supersonic spectrum of vibration frequencies, cavitation is considered acoustic [6].

During cavitation, the energy density of the sound field is transformed into a high energy density inside and around the bubble, which collapses over time. Consequently, energy is spent on the formation of shock waves, thermal energy, local electrification of bubbles, excitation of sonoluminescence, and the formation of free radicals [8]. In this case, during cavitation, there is a change in the rheological properties of the technological medium, such as viscosity, plasticity and elasticity [9]. Therefore, the determination of the parameters of acoustic treatment of technological media and energy requires the use of a computational model [10], which takes into account these changes. The key parameter of the evolution of gas and air bubbles in the acoustic field is the pressure that is formed in the contact zone of the "cavitator - medium" system [11-14]. The specified parameters and characteristics (Fig. 6.1) $[15,16]$.

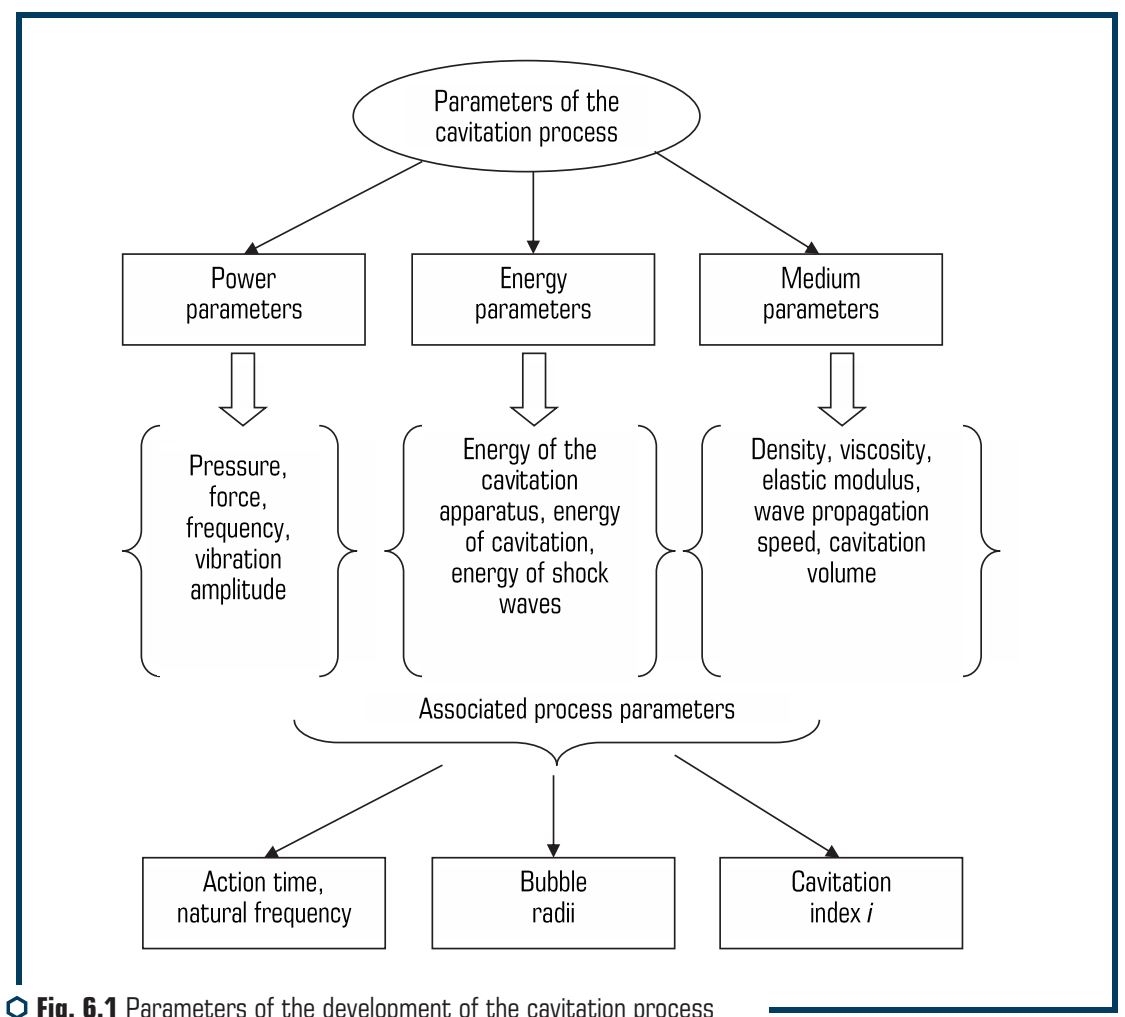

O Fig. 6.1 Parameters of the development of the cavitation process when processing technological media 
The dominant influence on the sequence of the cavitation process is exerted by the following acoustic parameters and properties of the medium $[17,18]$ :

$$
F=f\left\{A, A_{i}, f, v, W, P, L, t, I, p, \sigma, c, E, p, \mu\right\}
$$

where $F$ - functional (integral criterion for evaluating a process); $A$ - amplitude of oscillations of the contact zone "acoustic apparatus - medium» zone; $A_{i}$ - flow amplitude of medium oscillations at a distance $x_{i}$ from the boundary of the contact zone «acoustic apparatus - medium»; $f$ - vibration frequency of the acoustic apparatus; $v$ - speed of vibrations of the contact zone "acoustic apparatus - medium»; $W$ - energy, $P$ - power; $L$ - intensity; $t$ - time; $I$ - characteristic size of the medium in the direction of propagation of the acoustic wave in it; $p$ - the pressure on the medium; $\sigma$-stress in the medium; $c$ is the speed of propagation of an acoustic wave in a medium; $E$ - modulus of elasticity of the medium; $\rho$ - density of the medium; $\mu$ - coefficient of viscosity of the medium.

Integral parameters of function (6.1) are energy, intensity and power. Ultrasonic energy from the emitting surface of the ultrasonic apparatus to the medium undergoes several stages of transformation:

- accumulation of energy in cavitation bubbles during their formation and expansion;

- transformation of energy into energy of a shock wave during a burst of a cavitation bubble.

\subsection{DETERMINATION OF FUNCTIONAL DEPENDENCIES BETWEEN THE ACOUSTIC PARAMETERS OF THE CAVITATION APPARATUS AND THE RHEOLOGICAL PROPERTIES OF THE PROCESSING TECHNOLOGICAL MEDIA}

Let's consider the influence of the parameters of the cavitation process on the formation of the volume of the cavitating technological medium. By analogy with the general functional (6.1), the rate of change in the volume of bubbles $V$ can be represented by the following functional dependence:

$$
V(t)=f\left(t, R_{0}, l, n, \rho_{l}, \mu_{l}, \sigma, \rho_{g}, \mu_{g}, p_{e}, p_{i}\right)
$$

Taking time $t$, bubble radius $R_{0}$, density $\rho_{\text {, }}$ as the main independent parameters in terms of dimension and using the basic provisions of the theory of dimensions [19], let's reduce all parameters (6.2) to a dimensionless form with respect to the formed bubble volume: $t-$ time, [T]; $I$ - characteristic length in the direction of the wave motion of the bubbles, [L]; $R_{0}$ - initial bubble radius, $[L] ; n$ - the number of bubbles per unit volume, $\left[1 / L^{3}\right] ; \rho_{L}$ - density of the medium, $\left[M / L^{3}\right]$; $\mu_{L}-$ viscosity, [M/LT]; $\sigma$ - surface tension, $\left[\mathrm{M} / \mathrm{T}^{2}\right] ; \rho_{g}$ - gas density, $\left[\mathrm{M} / \mathrm{L}^{3}\right] ; \mu_{g}-$ gas viscosity, $[\mathrm{M} / \mathrm{LT}] ; p_{e}$ - external pressure, [M/LT2]; $p_{i}$ - pressure inside the bubbles, $\left[\mathrm{M} / \mathrm{LT}^{2}\right]$. Then the functional dependence (6.2) can be represented in dimensionless form: 


$$
\frac{V}{\frac{4}{3} \pi R_{0}^{3} / t}=f\left(\frac{l}{R_{0}} ; n R_{0}^{3} ; \frac{\mu_{l}}{\rho_{l} R_{0}^{2} / t}, \frac{\sigma}{\rho_{l} R_{0}^{3} / t^{2}}, \frac{\rho_{3}}{\rho_{l}}, \frac{\mu_{g}}{\rho_{l} R_{0}^{2} / t}, \frac{p_{e}}{\rho_{l} R_{0}^{2} / t^{2}}, \frac{p_{e}-p_{i}}{p_{l} R_{0}^{2} / t^{2}}\right) .
$$

The next analysis procedure (6.3) is to assess the importance of taking into account the components of this dependence on the rate of formation of the volume of the cavitating technological medium. If to accept the condition of bubble bursting time $\tau_{B}$ in the form [20]:

$$
\tau_{B}=0.915 R_{0} \sqrt{\frac{\rho_{l}}{\rho_{e}-\rho_{i}}},
$$

then dependence (6.3) can be re-formed into the following form:

$$
\frac{V}{\frac{4}{3} \pi R_{0}^{3} / \tau_{B}}=f\left(I ; N ; \frac{\mu_{l}}{\rho_{L} R_{0}^{2} / \tau_{B}}, \frac{\sigma}{\rho_{l} R_{0}^{3} / \tau_{B}^{2}}, \frac{\rho_{g}}{\rho_{l}}, \frac{\mu_{g}}{\rho_{l} R_{0}^{2} / \tau_{B}}, \frac{p_{e}}{\rho_{e}-p_{i}}, \frac{t^{2}}{\tau_{B}^{2}}\right) \text {. }
$$

For media with low viscosity at the stage of bubble burst, according to the data of [20], the viscosity and surface tension can be neglected. Then dependence (6.5) for such conditions can be simplified to the form:

$$
\frac{V}{\frac{4}{3} \pi R_{0}^{3} / \tau_{B}}=f\left(l ; N ; \frac{p_{e}}{p_{e}-p_{i}}, \frac{t^{2}}{\tau_{B}^{2}}\right) \text {. }
$$

The obtained dependence testifies to the importance of the influence of pressure, bubble diameter and burst time on the rate of formation of a volume of a cavitating medium with low viscosity. For other technological media, dependence (6.3) is used. The calculations of the numerical values of the volume of the cavitation zone depending on the intensity are given in Table 6.1.

Table 6.1 Numerical value of the formation of the volume of the cavitation zone, depending on the intensity

\begin{tabular}{lllllll}
\hline Intensity, $\mathbf{W} / \mathbf{c m}^{2}$ & $\mathbf{5 . 0}$ & $\mathbf{1 0 . 0}$ & $\mathbf{2 0 . 0}$ & $\mathbf{3 0 . 0}$ & $\mathbf{4 0 . 0}$ & $\mathbf{5 0 . 0}$ \\
\hline The volume of the cavitation zone, $\mathrm{m}^{3} \cdot 10^{-4}$ & 0.10 & 0.30 & 0.40 & 0.42 & 0.44 & 0.46 \\
\hline
\end{tabular}

The importance of the data in this table lies in the fact that the ratio of the volume of non-bursting $\Delta V_{1}$ (long-lived bubbles) to the volume of bubbles that burst $\Delta V_{b}$ is an estimate of the efficiency of the cavitation process:

$$
K_{V}=\Delta V_{l} / \Delta V_{b}
$$


In general, a number of criteria and key parameters have been determined, the use of which is proposed as an estimate in the calculation algorithms, depending on certain known initial data of the cavitator and the medium (Table 6.2). of the cavitation process of processing technological media The main set of criteria involves the assessment of the energetics of the process as a key characteristic, and taking into account possible changes in key parameters from the stage of nucleation of bubbles to the final stage - a burst of bubbles. Criteria that directly determine the reliability of the choice of the mode (harmonic or pulsed mode) are extremely important. These include criteria 8, 9 and 12. The importance of criterion 8 lies in the reliability of the selected speed of the cavitation apparatus, and criterion 9 is a direct indicator of the ratio of the burst time and the period of the technological process. The most numerical value of this criterion determines the provision of the minimum value of the ratio (6.7) and the possible expediency of using a pulsed mode of loading on the technological medium.

Table 6.2 Criteria and key parameters for evaluating the effectiveness of the cavitation process of processing technological media

\section{No. Criterion, parameter}

\section{Analytical dependence}

12

3

1 The intensity of the cavitation process by the type of vibration

1.1 Sinusoidal vibrations, $I, W / \mathrm{cm}^{2}$

$$
I=\frac{p^{2}}{2 \rho c} ; I=A^{2} \times f^{3}
$$

1.2 Two-frequency oscillations, $I, W / \mathrm{cm}^{2}$

$$
I=\frac{\alpha \times A}{4 \pi^{2} T} \times \frac{(1+k n)^{2}}{2}
$$

1.3 Multifrequency oscillations, $I, W / \mathrm{cm}^{2}$

$$
I=\frac{\alpha \times A}{4 \pi^{2} T} \times \frac{\left(1+\sum k_{i} n_{i}\right)^{2}}{2}
$$

1.4 Non-linear (non-sinusoidal) fluctuations, I, W/ $/ \mathrm{cm}^{2}$

$$
I=\frac{\alpha \times A}{4 \pi^{2} T}
$$

System synergy coefficient (efficiency), $k_{s}$

$$
k_{s}=E_{s} / E_{n \cdot x} \text {. }
$$

The rate of change in the stress state of the medium in time $v_{s . s}, \mathrm{~N} / \mathrm{m}^{2} \mathrm{~s}$

$v_{s . s}=\frac{d \sigma}{d t}$

Coefficient of the ratio of the volumes of long-lived and cavitating bubbles, $K_{v}$

$$
K_{v}=\Delta V_{d} / \Delta V_{c}
$$

5 Coefficient of energy change over time for the entire period of bubble processing, $\mu, \mathrm{J} / \mathrm{s}$

6 Energy absorption coefficient, ap, $\mathrm{m}^{-1}$

$$
\mu=1 / T\left(\ln E_{0} / E_{k}\right)
$$

$$
A_{p}=P_{s p} / I
$$

7 Coefficient of the ratio of wave resistances of the cavitation medium, $k_{r}$

$$
k_{r}=\frac{\rho_{k} c_{k}}{\rho_{c} c_{c}}=\left[\frac{1}{1+\frac{K \beta_{n}}{\beta_{0}}}\right]^{1 / 2}
$$




\section{Continuation of Table $\mathbf{6 . 2}$}

\begin{tabular}{|c|c|c|}
\hline 1 & 2 & 3 \\
\hline 8 & Speed ratio, $k_{v}$ & $K_{s}=v_{0} / c_{k}$ \\
\hline 9 & $\begin{array}{l}\text { Coefficient of the ratio of the burst time to } \\
\text { the time of the oscillation period, } k_{t}\end{array}$ & $k_{t}=\tau / T$ \\
\hline 10 & Contact zone work, $A_{c z}, \mathrm{~J}$ & $A_{c z}=\pi m_{c} x_{0}^{2} \omega^{2} \mu$ \\
\hline 11 & $\begin{array}{l}\text { Work on the formation of cavitation } \\
\text { bubbles, } A_{c b}, \mathrm{~J}\end{array}$ & $A_{c b}=\frac{4}{3} \pi R_{m}^{3} P_{0} N$ \\
\hline 12 & Specific work of the cavitator, $\bar{A}, \mathrm{~J}$ & $\bar{A}=\bar{P} \cdot t$ \\
\hline 13 & $\begin{array}{l}\text { Specific work of volume, } A_{c} \text { cavitating } \\
\text { medium, } J\end{array}$ & $A_{c}=E_{c} \Delta V$ \\
\hline 14 & $\begin{array}{l}\text { Coefficient of conversion of acoustic energy } \\
\text { into energy of shock waves, } \eta_{y}\end{array}$ & $\eta_{y}=\eta \frac{E_{y}}{E_{k}} \frac{T}{\tau}$ \\
\hline 15 & Productivity of the cavitation process, $\Delta P, \mathrm{~m}^{3} / \mathrm{s}$ & $\Delta P=k P / E_{c}$ \\
\hline 16 & Bubble displacement amplitude, $A_{b}, \mu \mathrm{m}$ & $A_{b}=\frac{1}{\omega} \sqrt{\frac{2 l}{\rho c}}$ \\
\hline 17 & Bubble speed amplitude, $v_{b}, \mu \mathrm{m} / \mathrm{s}$ & $v_{b}=\sqrt{\frac{2 l}{\rho c}}$ \\
\hline 18 & Bubble acceleration amplitude, $a_{b}, \mu \mathrm{m} / \mathrm{s}^{2}$ & $a_{b}=\omega \sqrt{\frac{2 l}{\rho c}}$ \\
\hline 19 & $\begin{array}{l}\text { Natural bubble oscillation frequency: } \\
\text { discrete model, } \omega_{n} \text {, rad/s }\end{array}$ & $\omega_{n}=\sqrt{\left[\frac{3 \gamma}{\rho R_{0}^{2}}\left(P_{0}+\frac{2 \sigma}{R_{0}}\right)-\frac{2 \sigma}{\rho R_{0}^{3}}+\frac{2 c_{n p}}{\rho R_{0}^{3}}\right]-\left(\frac{2 \pi \delta_{n p}}{\omega}\right)^{2}}$ \\
\hline 20 & $\begin{array}{l}\text { Natural bubble oscillation frequency: contin- } \\
\text { uous model, } \omega_{n} \text {, rad/s }\end{array}$ & $\omega_{n}=\frac{\pi}{2 /} \sqrt{\frac{\left(E^{\prime}+i E^{\prime \prime}\right)\left(t_{c}\right)}{\rho\left(t_{c}\right)}}$ \\
\hline 21 & Relative bubble size, kr & $K_{b}=R_{m} / R_{0}$ \\
\hline
\end{tabular}

The application of this or that criterion is due to the initial information and the set goal formulated before the researcher to select the model and parameters, or by the engineer to create the necessary acoustic wave system for a specific technological processing process or create a new technological medium.

A similar example can be given for creating the required acoustic wave system. To implement the criteria-based assessment of the justification of the rational choice of the structural-parametric system "acoustic apparatus - technological medium», an algorithm has been developed (Fig. 6.2).

The essence of the algorithm lies in the ability to vary not only the initial parameters and the layout of the cavitator relative to the processing medium, but also to determine the influence of 
variable parameters on the maximum value of a particular criterion (Table 6.2). Depending on the formulation of the problem, a criterion is selected, which is fixed in block 8. Further, in block 2 "Formation of the technological scheme», preliminary calculations are made for the mode of energy transfer to the medium in accordance with the selected criterion. An important stage of the algorithm is blocks 3 and 5 , which determine the physical and mathematical models based on the research results [7-9, 12-18]. It is in blocks 4, 6, 7 that the initial data are formed to determine the numerical values of the impact parameters and the limits of their rational use. The completion of the calculation is the parameters that serve as the initial information for making decisions to improve the rational design and technological parameters of the acoustic cavitator.

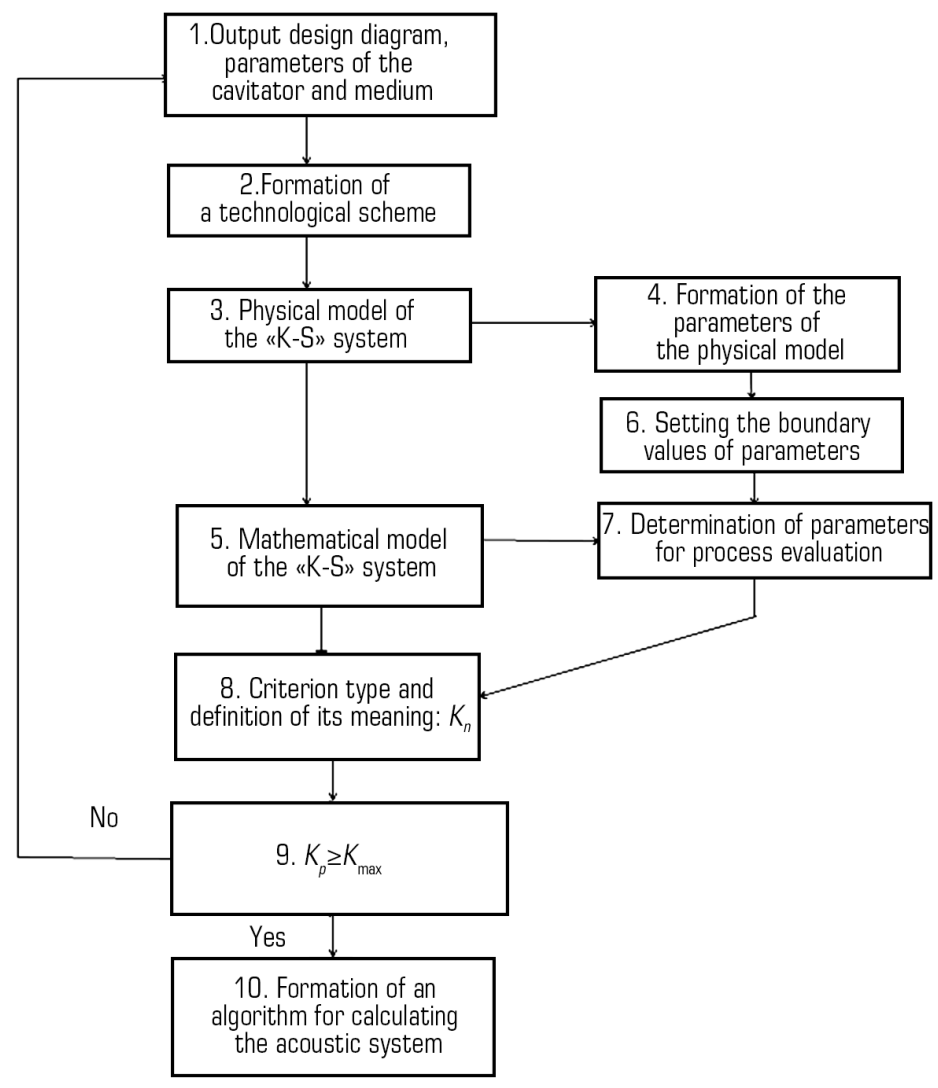

O Fig. 6.2 Scheme of criteria-based assessment of the justification of the rational choice of the "acoustic apparatus - technological medium» structural-parametric system 
This technology of the proposed algorithm is a fundamentally new system of automatic enumeration of parameters to fulfill the condition for ensuring the criterion of block 9 . The second important aspect of this algorithm is the creation of a control system for the processing of objects by an ultrasonic cavitation unit in the optimal operating mode. The energy absorption coefficient (criterion 6), which characterizes the change in the specific energy $P_{s p}$ and the ultrasound intensity $I$ in the irradiated medium, serves as a criterion for evaluating the efficiency of the acoustic treatment of this medium.

\subsection{DETERMINATION AND ASSESSMENT OF THE INFLUENCE OF THE WAVE IMPEDANCE OF THE MEDIUM ON THE ACTION OF THE ACOUSTIC APPARATUS}

An important parameter of the cavitation process is the wave resistance of the medium of the acoustic apparatus. The characteristic impedance is the ratio of the acoustic pressure $P_{a}$ to the vibration speed of the particles in the medium $v$ :

$$
Z_{a}= \pm P_{a} / v
$$

The importance of knowing the coefficient $Z_{a}$ is that it is an important characteristic of the interaction of the "acoustic apparatus - medium» system, not only as a resistance, but also as a characteristic of wave motion. Therefore, the obvious task of an effective acoustic device is its design, which ensures the transfer of maximum energy for the implementation of the cavitation process. That is why the signs should be taken into account in formula (6.9): the upper (plus) identifying the wave transmitted from the radiation surface into the medium (incident wave), and the lower (minus) for the wave traveling in the opposite direction, i.e. from the border of the system «apparatus - technological medium» (wave). Obviously, for efficient transmission of the energy of an acoustic wave, the properties of the apparatus and the medium must be consistent with each other.

This consistency consists in the fact that their wave supports must be the same, which is practically impossible in real conditions of the cavitation process. Indeed, the acoustic resistances for solid materials from which the emitting surface of the acoustic device is made, and the resistance of the technological medium, differ significantly from each other.

For example, such a hard material as sapphire has an acoustic resistance for longitudinal waves: $Z_{a}=44.3 \cdot 10^{6} \mathrm{~kg} /\left(\mathrm{m}^{2} \cdot \mathrm{s}\right)$, and for water $Z_{a}=1.5 \cdot 10^{6} \mathrm{~kg} /\left(\mathrm{m}^{2} \cdot \mathrm{s}\right)$, for air $\left.Z_{a}=4.27 \cdot 10^{2} \mathrm{~kg} / \mathrm{(m}^{2} \cdot \mathrm{s}\right)$ [21]. Comparing these digital values, it becomes obvious that in order to solve the problems of rational design of an acoustic apparatus and determine its parameters, it is necessary to analytically investigate the sequence of acoustic matching of the apparatus and the technological medium in order to obtain the conditions for maximum energy transfer to the processing medium. For this, the process of propagation of an acoustic wave from the radiation surface of the apparatus to the processing medium is considered (Fig. 6.3). 


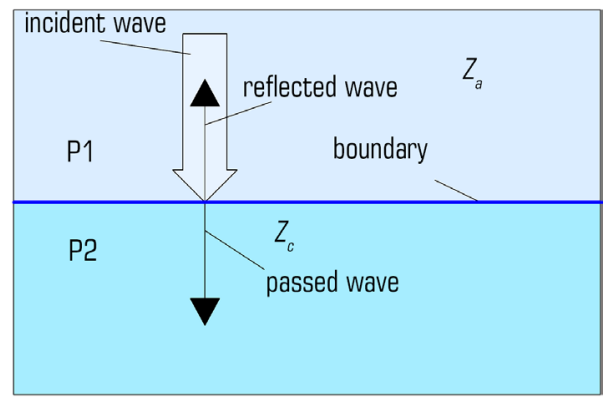

O Fig. 6.3 Passage and reflection of the incident wave at the interface of the "emitting surface of the cavitation apparatus - process medium» system

Let's assume that a plane acoustic wave along the $X$-axis from the apparatus to the boundary with the medium propagates with acoustic resistance $Z_{a}$, and in the medium at the border with the radiation surface of the apparatus along the same $X$-axis, due to the action of this resistance, wave resistance $Z_{c}$ arises. It is quite obvious that, in addition to the wave transmitted into the medium, a wave moving in the opposite direction arises at the interface between the radiation surface and the medium. Thus, a complex wave field is formed, which can be represented by the transmission and reflection coefficients of the wave in the form:

$$
K_{\text {ref }}=P_{\text {aref }} / P_{\text {ainc }} ; K_{\text {pas }}=P_{\text {ainc }} / P_{\text {aref }} .
$$

By analogy with solving the equation of motion, it is possible to write expressions for the incident and reflected waves of pressure and speed:

$$
P(x)=P_{\text {ainc }} e^{-i k_{1} x}+P_{\text {aref }} e^{i k_{1} x} ; v(x)=v_{x \text { inc }} e^{-i k_{1} x}+v_{\text {xref }} e^{i k_{1} x},
$$

where $k_{1}=\omega_{1} / c_{1}-$ the wavenumber; $i$ - imaginary unit.

Applying the condition of continuity of motion parameters in the contact zone of the «apparatus - medium» system (no violation of continuity):

$$
P_{a}=P_{e} ; v_{a}=v_{e}
$$

let's obtain:

$$
\frac{P_{\text {ainc }}}{Z_{a}}-\frac{P_{\text {aref }}}{Z_{a}}=\frac{P_{\text {apas }}}{Z_{e}} .
$$


Dividing the left and right sides by the amplitude of the acoustic pressure $P_{\text {ainc }}$ and using (6.9) let's obtain expressions for determining the reflection and transmission coefficients of the wave:

$$
K_{\text {ref }}=\left(Z_{e}-Z_{a}\right) /\left(Z_{e}+Z_{a}\right) ; K_{\text {pas }}=2 Z_{e} /\left(Z_{e}+Z_{a}\right) \text {. }
$$

The condition for determining the wave impedance for its maximum transmission can be realized by introducing a compensator between the boundary of the radiation surface of the apparatus and the medium, which plays the role of resistance to the load and the reflection of acoustic waves exclusively in the zone of the apparatus (Fig. 6.4).

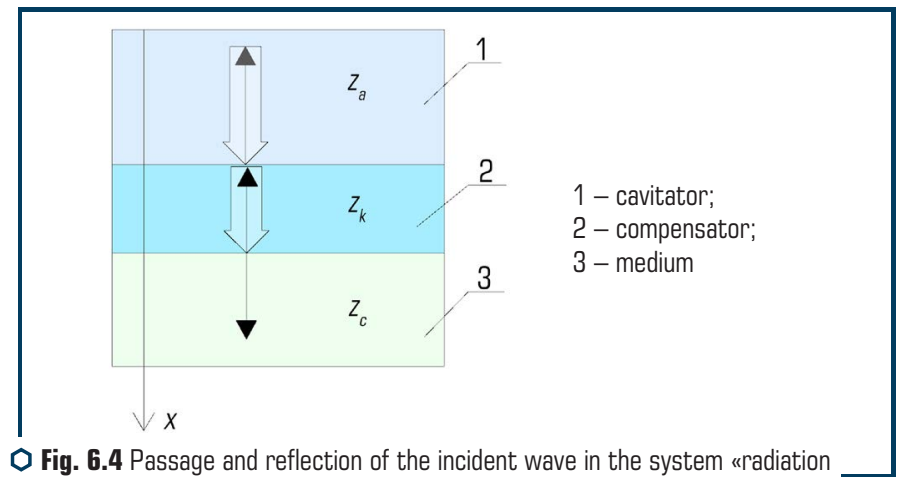
surface of the cavitation apparatus - compensator - technological medium»

In this case, the load resistance must be equal to the wave resistance of the medium: $Z_{k}=Z_{e}$. Using solution (6.10) with the replacement $x=I$, where $I$ - the length of the radiation surface of the apparatus, where the wave propagates, let's obtain the resistance in the section $(x=-l)$ :

$$
Z_{i n}(x=-l)=\frac{P_{a}(-l)}{v(-l)}=Z_{a}\left[\frac{e^{i k_{1} l}+k_{r e f} 5^{-k_{l} l}}{e^{i k_{1} l}-k_{\text {ref }} 5^{-i k_{l}}}\right] .
$$

Taking into account expression (6.14):

$$
Z_{\text {in }}=-I=Z_{a} \frac{Z_{e} \cos k_{1} l+i Z_{a} \sin k_{1} l}{Z_{a} \cos k_{1} l+i Z_{e} \sin k_{1} l} \text {. }
$$

If to assume that a compensator with a length is installed between the radiation surface of the apparatus and the medium $I=\lambda / 4$, where $\lambda$ - the wavelength in the compensator, then let's obtain the following dependence:

$$
k_{1} l=(2 \pi / \lambda) /(\lambda / 4)=\pi / 2
$$


Substituting (6.16) into (6.15), let's obtain an expression for determining the input wave impedance:

$$
Z_{\text {in }}(\lambda / 4)=Z_{a}^{2} / Z_{e}
$$

So, choosing the value of the input resistance of the compensator with a length of $\lambda / 4$, let's obtain the condition for maximum transmission, according to which the characteristic impedance of the apparatus and the compensator is in agreement. Indeed, by placing an auxiliary layer of material with such an acoustic impedance between the boundary of the apparatus and the medium, it is possible to ensure the equality of the acoustic impedance of the apparatus and the equivalent transmission line. Then the waves of reflection from both boundaries of the additionally installed layer will be equal to the amplitude and will move in antiphase direction, which will lead to their mutual compensation. And the shift between the phases of movement for $180^{\circ}$ is provided by the difference in wave path between the boundaries at half the wavelength. Equality of amplitudes is ensured by the optimal choice of the wave impedance of the compensator. If the compensator has its own parameters: resistance $Z_{k}$, wavenumber $k_{k}$ and thickness $l k$, then provided that $I_{k}=\lambda_{k} / 4$ is the input resistance at the boundary $x=-I_{k}$ :

$$
Z_{\text {in }}=Z_{k}^{2} / Z_{e} \text {. }
$$

To fulfill the condition under which there were no reflected waves from the section $x=-I_{k}$, the input impedance (6.17) must be equal to the acoustic impedance of the apparatus $Z_{1}$ :

$$
Z_{a}=Z_{k}^{2} / Z_{e}
$$

From (6.19) let's obtain an expression for calculating the acoustic resistance of the compensator:

$$
Z_{k}=\sqrt{Z_{a} Z_{e}}
$$

To apply dependence (3.72), which allows matching the acoustic impedance of the apparatus and the medium, it is necessary to determine the real numerical values of the wave impedance of technological media under conditions of their cavitation treatment.

One of the most important parameters, on which the wave impedance of the technological medium depends, is the wave propagation speed $c$. In terms of physical content, the dependence of the wave propagation speed determines the ratio of elastic $(E)$ and inertial (mass $\rho$ ) characteristics of the technological medium:

$$
c=\sqrt{E / \rho} .
$$

An experimental device was created to measure the speed of wave propagation in a technological medium (Fig. 6.5). 


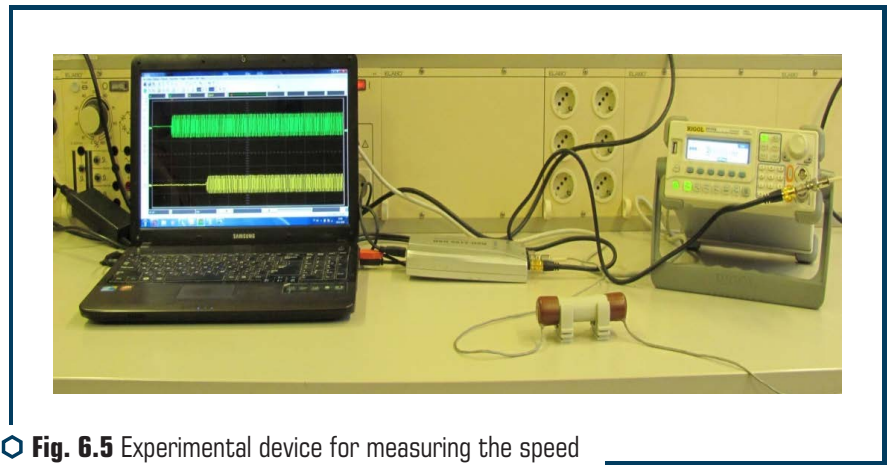
of propagation of waves in a technological medium

The essence of the device is as follows. An electrical signal of a fixed ultrasonic frequency is referenced from the pulse generator to the transmitter. The sensor, which in this case is a transmitter and receiver, converts the incoming signal into elastic vibrations of the same frequency (inverse piezoelectric effect) passing through the layer of the technological medium. The receiver converts elastic vibrations of ultrasonic frequency into an electrical signal of the same frequency (direct piezoelectric effect) and sends the signal to the computer screen. The computer screen displays the generator impulse and the signal transmitted through the tube with the process medium (Fig. 6.6).

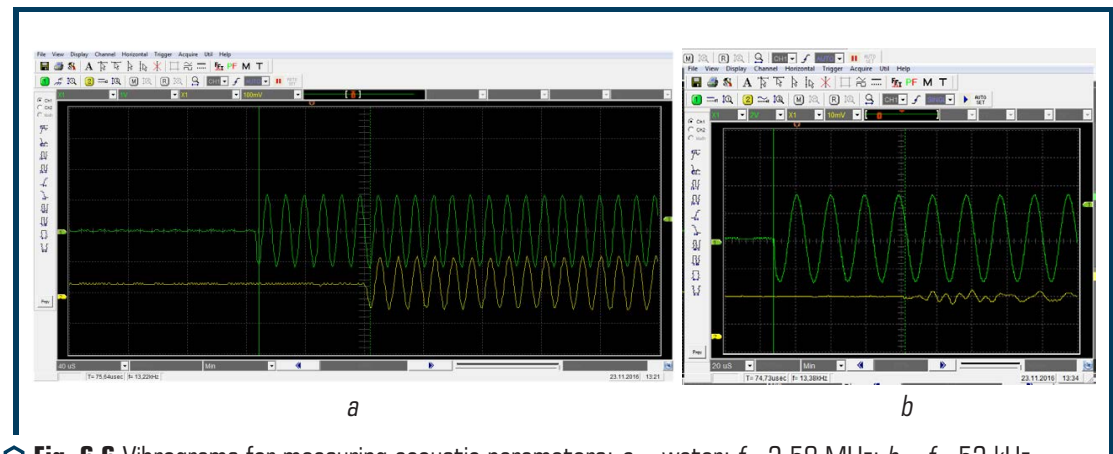

Fig. 6.6 Vibrograms for measuring acoustic parameters: $a$ - water: $f=2.58 \mathrm{MHz} ; b-f=52 \mathrm{kHz}$

The distance between them $h$ characterizes the time $t$ of passage of elastic vibrations from the source to the reflector and back. Consequently, the speed of propagation of waves in the technological medium is determined by the formula:

$$
c=h / t \text {. }
$$




\subsection{METHODOLOGY AND ALGORITHM FOR DETERMINING THE RATIONAL PARAMETERS OF THE WORKING PROCESS OF ACOUSTIC TREATMENT OF TECHNOLOGICAL MEDIA}

An algorithm was developed to calculate the parameters of the "cavitator - technological medium» ultrasonic cavitation system (Fig. 6.7).

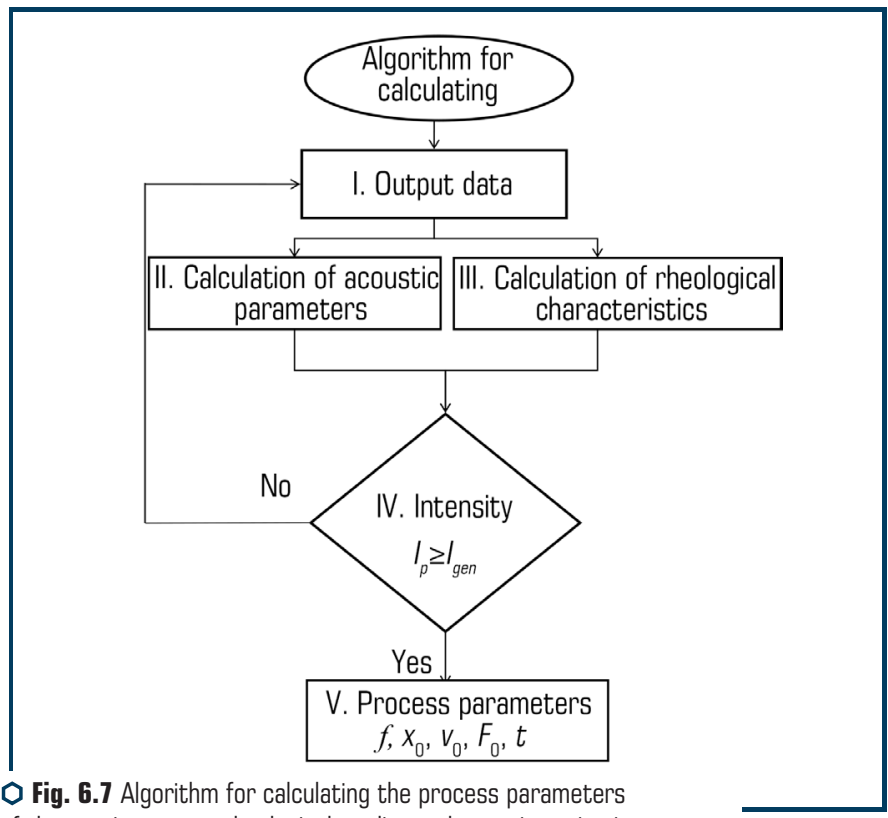

of the "cavitator - technological medium» ultrasonic cavitation system

The initial parameters used for the calculation are formed depending on the specific processing process or the creation of a new technological medium. The first step in the process of selecting the initial parameters is to substantiate the general scheme of the structural-parametric system "acoustic apparatus - technological medium» (Fig. 6.1) and the mode of action of the transducer on the medium. The structural-parametric scheme selected according to the algorithm (blocks 2-4, Fig. 6.1) requires specification of the limiting values of the parameters (block 6, Fig. 6.1) and the choice of a mathematical model of the "K-S" system (block 5, Fig. 6.1). In the future, the procedure for formulating the initial data, the calculation of acoustic parameters and the calculation of the rheological characteristics of the medium are carried out [4, 7-9, 11-15, 18-20, 22-26]. The criterion for the reliability of the calculation is the intensity (block IV, Fig. 6.7). When the numerical value of the intensity is provided, the procedure for calculating the process parameters is completed (block V, Fig. 6.7). 


\subsection{DISCUSSION OF RESEARCH RESULTS}

The value of the input resistance of the compensator of length $\lambda / 4$ is determined and the condition of maximum transmission is obtained, according to which the wave impedance of the apparatus and the compensator is in agreement. By placing an auxiliary layer of material with such an acoustic impedance between the boundary of the apparatus and the medium, equality of the acoustic impedance of the apparatus and the equivalent transmission line is ensured. Then the waves of reflection from both boundaries of the additionally installed layer will be equal to the amplitude and will move in antiphase direction, which will lead to their mutual compensation. And the shift between the phases of movement for $180^{\circ}$ is provided by the difference in wave path between the boundaries at half the wavelength. As a result, the maximum transfer of energy from the acoustic device to the technological medium is created. For the implementation of the criterion assessment of the justification of the rational choice of the "acoustic apparatus - technological medium» structural-parametric system, an algorithm is proposed (Fig. 6.1). The essence of the algorithm lies in the ability to vary not only the initial parameters and the layout of the cavitator relative to the processing medium, but also to determine the influence of variable parameters on the maximum value of a particular criterion (Table 6.2). The necessary degree of influence and consideration of stages, rational modes and parameters for the development of techniques that implement an increase in the efficiency of the cavitation process in conditions of minimizing energy costs have been determined.

\section{CONCLUSIONS TO SECTION 6}

1. The estimation and methods of research of parameters of acoustic treatment of technological media have been carried out. The functional relationships between the acoustic parameters of the cavitation apparatus and the rheological properties of the processing technological media have been revealed. The process of staged acoustic treatment of technological media is described.

2. The analytical dependences of the determination of the main parameters of the cavitation apparatus have been obtained and the regularities of the processes of staged acoustic treatment of technological media in conditions of energy minimization have been established.

3. A number of criteria and key parameters have been determined, the use of which is carried out as an assessment in the calculation algorithm, depending on certain known initial data of the cavitator and the medium. The values of the input resistance of the compensator have been determined and the condition for the maximum transfer of energy from the acoustic apparatus to the technological medium has been obtained.

4. An algorithm is proposed to substantiate the rational choice of the "acoustic apparatus technological medium» structural-parametric system, which allows to vary not only the initial parameters and the layout of the cavitator relative to the processing medium, but also to determine the effect of variable parameters on the maximum value of a particular criterion. 


\section{REFERENCES}

1. Kaletnik, H., Sevostianov, I., Bulgakov, V., Holovach, I., Melnik, V., Ihnatiev, Ye., Olt, J. (2020). Development and examination of high-performance fluidised-bed vibration drier for processing food production waste. Agronomy Research, 18 (4), 2391-2409. doi: http://doi.org/ 10.15159/ar.20.234

2. Bulgakov, V., Sevostianov, I., Kaletnik, G., Babyn, I., Ivanovs, S., Holovach, I., Ihnatiev, Y. (2020). Theoretical Studies of the Vibration Process of the Dryer for Waste of Food. Rural Sustainability Research, 44 (339), 32-45. doi: http://doi.org/10.2478/plua-2020-0015

3. Kaletnik, G., Tsurkan, O., Rimar, T., Stanislavchuk, 0. (2020). Determination of the kinetics of the process of pumpkin seeds vibrational convective drying. Eastern-European Journal of Enterprise Technologies, 1 (8 (103)), 50-57. doi: http://doi.org/10.15587/17294061.2020.195203

4. Bernyk, I. M. (2011). Osnovni zasady proektuvannia mashyn i obladnannia pererobnykh vyrobnytstv. Teoriia i praktyka budivnytstva, 8, 6-9.

5. Vitenko, T. M. (2009). Hidrodynamichna kavitatsiia u masoobminnykh, khimichnykh i biolohichnykh protsesakh. Ternopil: Vydavnytstvo TDTU im. I Puliuia, 224.

6. Khmelev, V. N., Slivin, A. N., Barsukov, R. V., Tsyganok, S. N., Shalunov, A. V. (2010). Primenenie ultrazvuka vysokoi intensivnosti v promyshlennosti. Biisk: Izd-vo Alt. gos. tekhn. un-ta, 203.

7. Nazarenko, I., Dedov, O., Bernyk, I., Rogovskii, I., Bondarenko, A., Zapryvoda, A. et. al. (2020). Determining the regions of stability in the motion regimes and parameters of vibratory machines for different technological purposes. Eastern-European Journal of Enterprise Technologies, 6 (7 (108)), 71-79. doi: http://doi.org/10.15587/1729-4061.2020.217747

8. Luhovskyi, O. F., Bernyk, I. M. (2014). Vstanovlennia osnovnykh parametriv vplyvu tekhnolohichnoho seredovyshcha na robochyi protses ultrazvukovoi kavitatsiinoi obrobky. Vibratsii $v$ tekhnitsi ta tekhnolohiiakh, 3 (75), 121-126.

9. Bernyk, I. M. (2015). Enerhetyka kavitatsiinoi obrobky tekhnolohichnoho seredovyshcha. Naukovi pratsi ONAKhT, 1 (47), 123-129.

10. Luhovskaia, E. A., Yakhno, O. M., Bernyk, Y. N. (2012). Model of Technological Process of Ultrasonic Clearing of Elastic Surfaces Management. Naukovi pratsi Don NTU. Seriia: Hirnychoelektromekhanichna, 23 (196), 154-166.

11. Luhovskyi, O. F., Gryshko, I. A., Bernyk, I. M. (2018). Enhancing the Efficiency of Ultrasonic Wastewater Disinfection Technology. Journal of Water Chemistry and Technology, 40 (2), 95-101. doi: http://doi.org/10.3103/s1063455×18020078

12. Bernyk, I., Luhovskyi, 0., Nazarenko, I. (2018). Effect of rheological properties of materials on their treatment with ultrasonic cavitation. Materiali in Tehnologije, 52 (4), 465-468. doi: http://doi.org/10.17222/mit.2017.021

13. Bernyk, I., Luhovskyi, O., Wojcik, W., Shedreyeva, I., Karnakova, G. (2019). Theoretical Investigations of the Interaction of Acoustic Apparatus with Technological Environment 
Working Process. Przeglad Elektrotechniczny, 1 (4), 32-37. doi: http://doi.org/10.15199/ 48.2019.04.06

14. Luhovskyi, O., Bernyk, I., Gryshko, I., Abdulina, D., Zilinskyi, A.; Stryczek, J., Warzyńska, U. (Eds.) (2021). Mobile Equipment for Ultrasonic Cavitation Inactivation of Microorganisms in the Liquid Environment. NSHP 2020. Lecture Notes in Mechanical Engineering. Cham: Springer, 272-281. doi: http://doi.org/10.1007/978-3-030-59509-8_24

15. Bernyk, I., Luhovskyi, 0., Nazarenko, I. (2016). Research staff process of interaction and technological environment in developed cavitation. Journal of Mechanical Engineering the National Technical University of Ukraine "Kyiv Polytechnic Institute», 1 (76), 12-19. doi: http://doi.org/10.20535/2305-9001.2016.76.39735

16. Bernyk, I. M. (2013). Intensification of technological processes of treatment of food environments. Vibratsii v tekhnitsi ta tekhnolohiiakh, 3 (71), 109-115.

17. Bernyk, I. M. (2014). Doslidzhennia parametriv kavitatsiinoho protsesu obrobky tekhnolohichnykh seredovyshch. Naukovo-tekhnichnyi zhurnal Tekhnika budivnytstva, 33, 21-26.

18. Bernyk, I. M. (2018). Investigation of the viscosity of dispersed media under conditions of their intensive processing. Tekhnika, enerhetyka, transport APK, 1 (100), 62-67.

19. Ohirko, O. I., Halaiko, N. V. (2017). Teoriia ymovirnostei ta matematychna statystyka. Lviv: LvDUVS, 292.

20. Sirotiuk, M. G., Gavrilov, L. R. (2008). Akusticheskaia kavitatsiia. Moscow: Nauka, 271.

21. Goliamina, I. P. (Ed.) (1979). Ultrazvuk. Malenkaia entsiklopediia. Moscow: Sovetskaia entsiklopediia, 400.

22. Nazarenko, I., Svidersky, A., Kostenyuk, A., Dedov, O., Kyzminec, N., Slipetskyi, V. (2020). Determination of the workflow of energy-saving vibration unit with polyphase spectrum of vibrations. Eastern-European Journal of Enterprise Technologies, 1 (7 (103)), 43-49. doi: http://doi.org/10.15587/1729-4061.0.184632

23. Nazarenko, I., Gavryukov, 0., Klyon, A., Ruchynsky, N. (2018). Determination of the optimal parameters of a tubular belt conveyor depending on such an economical. Eastern-European Journal of Enterprise Technologies, 3 (1 (93)), 34-42. doi: http://doi.org/10.15587/17294061.2018.131552

24. Nazarenko, I. I., Ruchynskyi, M. M., Sviderskyi, A. T., Kobylanska, I. M., Harasim, D., Kalizhanova, A., Kozbakova, A. (2019). Development of energy-efficient vibration machines for the buiding-and-contruction industry. Przeglad Elektrotechniczny, 95 (4), 53-59. doi: http://doi.org/ 10.15199/48.2019.04.10

25. Nazarenko, I., Gaidaichuk, V., Dedov, O., Diachenko, 0. (2018). Determination of stresses and strains in the shaping structure under spatial load. Eastern-European Journal of Enterprise Technologies, 6 (7 (96)), 13-18. doi: http://doi.org/10.15587/1729-4061.2018.147195

26. Nazarenko, I., Gaidaichuk, V., Dedov, O., Diachenko, 0. (2017). Investigation of vibration machine movement with a multimode oscillation spectrum. Eastern-European Journal of Enterprise Technologies, 6 (1 (90)), 28-36. doi: http://doi.org/10.15587/1729-4061.2017.118731 